\title{
Dispersal alters bacterial diversity and composition in a natural community
}

\author{
Michaeline BN Albright and Jennifer BH Martiny \\ Department of Ecology and Evolutionary Biology, University of California, Irvine, CA, USA
}

\begin{abstract}
Dispersal is central to the evolution and maintenance of microbial diversity. Quantifying microbial dispersal and its role in shaping communities remains a challenge, however. Here, we manipulated a bacterial community's dispersal rate in a grassland ecosystem and test whether this altered diversity and composition. We constructed bags of two nylon mesh sizes that allowed more or less bacterial movement and filled them with an edible or inedible substrate, irradiated plant litter or nylon sheets. We measured changes in bacterial abundance (using flow cytometry) and composition (using 16S amplicon sequencing) in the bags weekly over 5 months. The dispersal treatment altered bacterial colonization rates and led to differences in the abundance, richness, evenness and composition of communities. Overall, the study demonstrates that dispersal influences the assembly of this natural bacterial community.
\end{abstract}

The ISME Journal (2018) 12, 296-299; doi:10.1038/ismej.2017.161; published online 20 October 2017

\section{Introduction}

Dispersal, or the movement of organisms, has an important role in the evolution and maintenance of biodiversity (Leibold et al., 2004; Cottenie, 2005). Recent biogeographic studies and field experiments suggest that, as with larger organisms, microorganisms are dispersal-limited (Bell, 2010; Lindstrom and Ostman, 2011; Hanson et al., 2012) or, in other words, the probability of a bacterium moving away from a location varies with distance. Because of this limitation, dispersal rates can influence both diversity (richness and evenness) and composition of microbial communities (Whitaker et al., 2003; Horner-Devine et al., 2004; Martiny et al., 2011; Andam et al., 2016). In addition, dispersal may have an impact on communities through mass effects (Evans et al., 2017). However, quantifying the dispersal of microorganisms is a challenge because of their small size and high abundance (Nemergut et al., 2013); hence, the relationship between dispersal rates and microbial diversity or composition remains to be tested. Indeed, these relationships are likely complex and dependent on environmental context (Chase, 2007; Louca et al., 2016; Evans et al., 2017). Thus, field experiments will be required to elucidate the role of dispersal in shaping microbial communities.

Correspondence: MBN Albright, Department of Ecology and Evolutionary Biology, University of California, 321 Steinhaus Hall, Irvine, CA 92697-2525, USA.

E-mail: nelsonmb@uci.edu

Received 30 March 2017; revised 4 August 2017; accepted 22 August 2017; published online 20 October 2017
Here, we tested whether varying a community's dispersal rate alters the diversity and composition of a bacterial community. We focused on bacterial communities on plant litter, the top layer of soil, in a southern California grassland (Martiny et al., 2017). To manipulate the dispersal rate (the number of cells migrating into/out of a community per time), we constructed bags from two nylon mesh sizes. The high dispersal rate treatment $(18.0 \mu \mathrm{m}$; hereafter 'open') allowed for the migration of bacteria and larger microorganisms through the bags, whereas the low dispersal rate treatment $(0.22 \mu \mathrm{m}$; 'closed') substantially reduced dispersal (Allison et al., 2013; Martiny et al., 2017). To disentangle the influence of dispersal alone versus growth and successional dynamics, we also manipulated the substrate inside the bags. Half of the bags within each dispersal treatment contained an edible substrate (irradiated plant litter), and half contained an inedible substrate (irradiated nylon sheet), where microbes could land but not grow. In total, we deployed 192 bags into the field and collected three replicates per treatment at 16 time points over the course of 5 months. For each bag, we measured total cell abundance using flow cytometry and characterized the bacterial community using $16 \mathrm{~S}$ amplicon sequencing. During the last 2 months of the experiment, we also assayed samples from surrounding plant litter (detailed methods in Supplementary Information).

\section{Results and discussion}

Bacterial abundance differed by dispersal treatment (Figure 1a). In the litter-containing bags, abundance 


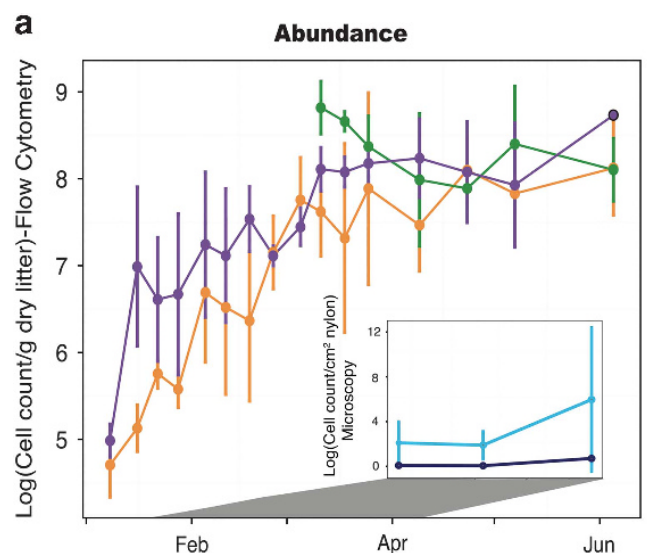

b

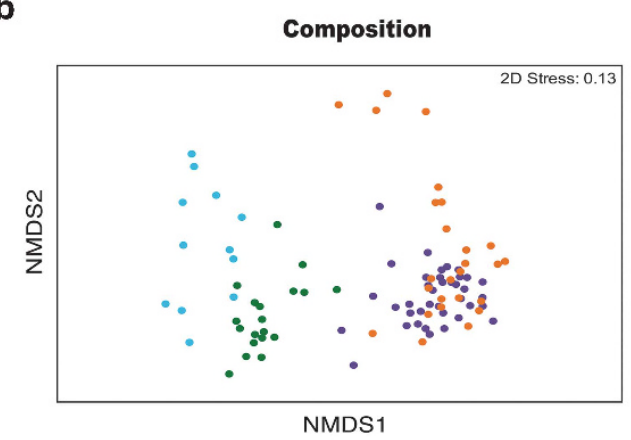

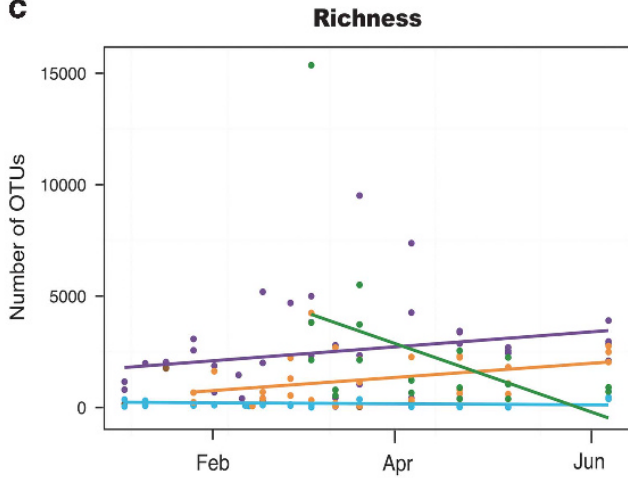

d

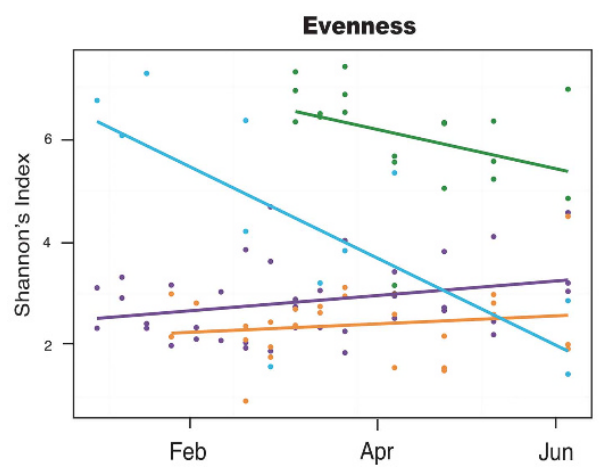

Figure 1 Effects of dispersal limitation on bacterial (a) abundance, (b) composition, as assayed by 16S sequencing, (c) richness and (d) evenness, after rarefaction to standardize for sequencing effort among samples. Error bars in a are 1+1 s.e. The four treatment types included litter-containing open bags (purple), litter-containing closed bags (orange), nylon-containing open bags (light blue), nyloncontaining closed bags (dark blue). Plant litter samples from the surrounding environment (green) were also collected for comparison.

was 151 times higher in the open versus closed treatment after just 1 week $\left(2.3 \times 10^{7}\right.$ per g dry litter and $1.5 \times 10^{5}$ per g dry litter, respectively; $t$-test: $\left.t_{4}=3.36, P=0.03\right)$. This difference persisted for the first 7 weeks of the experiment, indicating that the closed bags successfully lowered bacterial dispersal rates (Supplementary Table S1). Notably, however, abundance also increased in the closed bags such that average abundance in the open and closed treatments did not significantly differ after 7 weeks (Supplementary Table S1). After 11 weeks, bacterial cell counts leveled off in both open and closed bags at $2.1 \times 10^{8}$ cells per $g$ dry litter, similar to that observed in the surrounding plant litter (Figure 1a). Thus, as with the phyllosphere (Remus-Emsermann et al., 2012), litter communities appear to be subject to a carrying capacity, and the capacity in our litter bags was similar to that of the surrounding, litter environment.

The open and closed nylon-containing bags also differed in their abundance; additionally, overall abundance was greatly reduced because of lack of growth. Bacterial abundance in the open bags (113 cells per $\mathrm{cm}^{2}$ nylon) was on average 330 times higher than that in the closed bags ( 0.34 cells per $\mathrm{cm}^{2}$ nylon; analysis of covariance; dispersal treatment: $\mathrm{F}_{1,14}=20.6, P<0.001$; inset in Figure 1a). We were unable to PCR-amplify DNA from the closed nylon- containing bags, confirming that dispersal was greatly reduced by the smaller mesh size.

Higher community dispersal rates led to increased bacterial diversity. Observed richness was significantly higher in the open versus closed littercontaining bags (Figure 1c and Supplementary Table S1). Richness also appeared limited by dispersal in the litter-containing bags, as it increased significantly over time. Furthermore, higher dispersal increased evenness in the litter-containing bags (Figure 1d and Supplementary Table S1). In general, growth on the irradiated litter led to more even communities in the later stages of the experiment, similar to the successional dynamics of a sterile substrate by marine taxa (Datta et al., 2016). In contrast, evenness in the open nylon-containing bags decreased over time, reflecting the pattern of the surrounding litter community (Figure 1d). We suspect that this decline in evenness is due to typical seasonal changes at this grassland site (Supplementary Figure S1; Matulich et al., 2015).

The dispersal rate also influenced bacterial composition (Figures $1 \mathrm{~b}$ and 2 and Supplementary Table S2). The closed litter-containing bags had significantly higher within-treatment variation than either the open litter-containing bags or the environmental litter (PERMDISP; $P=0.02$ and $P=0.004$, respectively). Thus, lower bacterial dispersal rates appear 


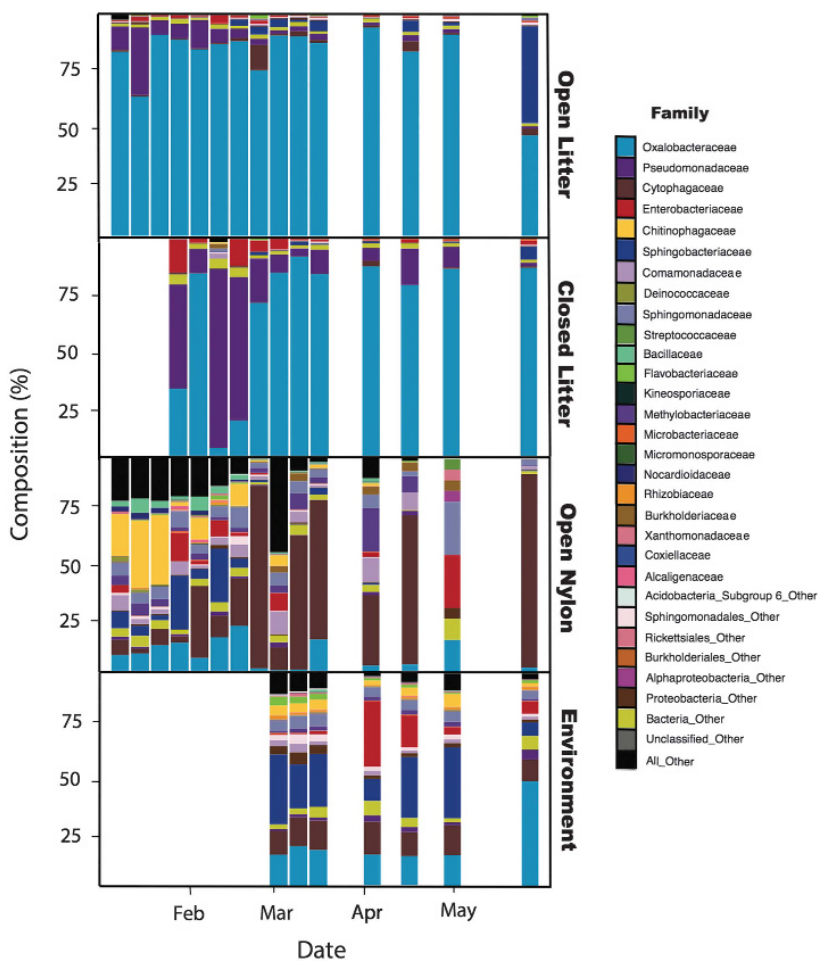

Figure 2 Relative abundance of bacterial families found in each treatment type (litter-containing open bags, litter-containing closed bags and nylon-containing open bags) and the surrounding plant litter (environment), averaged across each time point.

to increase ecological drift and result in more divergent composition (Hanson et al., 2012; Evans et al., 2017). The nylon-containing bags, which did not allow for growth, were more representative of the surrounding plant litter community than the littercontaining bags (Figures 1b and 2, Supplementary Table S3). Presumably, the nylon-containing bags are a random subsample of the surrounding community, whereas the communities in the litter-containing bags are in the early stages of succession and, therefore, are also influenced by growth and competition. Still, relative abundance of individual taxa in both the open nylon- and open litter-containing bags was positively correlated with the relative abundance of taxa in the environment $\left(R^{2}=0.77\right.$ and 0.76 , respectively, both $P<0.001$; Supplementary Figure S2). These strong correlations suggest that bacterial dispersal occurs primarily passively in this system, as taxa generally colonize the bags in proportion to their abundance on the surrounding plant litter. However, dispersal rates among taxa could depend on traits such as size, adhesive ability and, in the case of an edible substrate, competitive ability. Thus, it is notable that a Cytophagaceae taxon (genus Hymenobacter), previously characterized as a common atmospheric bacterium (Yooseph et al., 2013; Barberan et al., 2015), was more abundant on the nylon than on the environmental litter (Figure 2, Supplementary Figure S2). Similarly, an Oxalobacteriaceae taxon (genus Massilia) was more abundant in the litter bag samples than in the environment (Figure 2 and Supplementary Figure S2), suggesting that this taxon has a growth advantage during early litter colonization. Finally, we note that, although the mesh size of the open bags was small, we cannot exclude the possibility that they allowed a greater number of grazers to colonize, which may have contributed to differences in bacterial composition between the dispersal treatments.

\section{Conclusions}

This experiment reveals that bacterial dispersal, like selection by the litter substrate, contributes to the diversity and composition of this bacterial community on grassland litter. Our study also demonstrates the feasibility of manipulating bacterial dispersal in the field, offering the potential to disentangle the processes contributing to microbial community assembly (Hanson et al., 2012; Nemergut et al., 2013). Future work might consider the impacts of dispersal differences across ecosystems for community assembly and functioning.

\section{Conflict of Interest}

The authors declare no conflict of interest.

\section{Acknowledgements}

We thank Claudia Weihe for assistance with field sampling and laboratory methods. We thank Lucía Vivanco, Alexander Chase, Kendra Walters, Sydney Glassman and John Dunbar for comments on earlier versions of the manuscript. This work was supported by a US Department of Education Graduate Assistance in Areas of National Need (GAANN) fellowship to MA and the US Department of Energy, Office of Science, Office of Biological and Environmental Research (BER), under Award Number DE-PS02-09ER09-25 to JM.

\section{References}

Allison SD, Lu Y, Weihe C, Goulden ML, Martiny AC, Treseder KK et al. (2013). Microbial abundance and composition influence litter decomposition response to environmental change. Ecology 94: 714-725.

Andam CP, Doroghazi JR, Campbell AN, Kelly PJ, Choudoir MJ, Buckley DH. (2016). A latitudinal diversity gradient in terrestrial bacteria of the genus Streptomyces. Mbio 7: e02200-e02215.

Barberan A, Ladau J, Leff JW, Pollard KS, Menninger HL, Dunn RR et al. (2015). Continental-scale distributions of dust-associated bacteria and fungi. Proc Natl Acad Sci USA 112: 5756-5761.

Bell T. (2010). Experimental tests of the bacterial distancedecay relationship. ISME J 4: 1357-1365.

Chase JM. (2007). Drought mediates the importance of stochastic community assembly. Proc Natl Acad Sci USA 104: 17430-17434. 
Cottenie K. (2005). Integrating environmental and spatial processes in ecological community dynamics. Ecol Lett 8: $1175-1182$.

Datta MS, Sliwerska E, Gore J, Polz MF, Cordero OX. (2016). Microbial interactions lead to rapid micro-scale successions on model marine particles. Nat Commun 7: 11965.

Evans S, Martiny JB, Allison SD. (2017). Effects of dispersal and selection on stochastic assembly in microbial communities. ISME J 11: 176-185.

Hanson CA, Fuhrman JA, Horner-Devine MC, Martiny JBH. (2012). Beyond biogeographic patterns: processes shaping the microbial landscape. Nat Rev Microbiol 10: $497-506$.

Horner-Devine MC, Lage M, Hughes JB, Bohannan BJM. (2004). A taxa-area relationship for bacteria. Nature 432: 750-753.

Leibold MA, Holyoak M, Mouquet N, Amarasekare P, Chase JM, Hoopes MF et al. (2004). The metacommunity concept: a framework for multi-scale community ecology. Ecol Lett 7: 601-613.

Lindstrom ES, Ostman O. (2011). The importance of dispersal for bacterial community composition and functioning. PLoS One 6: e25883.

Louca S, Jacques SMS, Pires APF, Leal JS, Srivastava DS, Parfrey LW et al. (2016). High taxonomic variability despite stable functional structure across microbial communities. Nat Ecol Evol 1: 0015.
Martiny JB, Martiny AC, Weihe C, Lu Y, Berlemont R, Brodie EL et al. (2017). Microbial legacies alter decomposition in response to simulated global change. ISME J 11: 490-499.

Martiny JBH, Eisen JA, Penn K, Allison SD, Horner-Devine MC. (2011). Drivers of bacterial betadiversity depend on spatial scale. Proc Natl Acad Sci USA 108: 7850-7854.

Matulich KL, Weihe C, Allison SD, Amend AS, Berlemont R, Goulden ML et al. (2015). Temporal variation overshadows the response of leaf litter microbial communities to simulated global change. ISME J 9: 2477-2489.

Nemergut DR, Schmidt SK, Fukami T, O'Neill SP, Bilinski TM, Stanish LF et al. (2013). Patterns and processes of microbial community assembly. Microbiol Mol Biol Rev 77: 342-356.

Remus-Emsermann MNP, Tecon R, Kowalchuk GA, Leveau JHJ. (2012). Variation in local carrying capacity and the individual fate of bacterial colonizers in the phyllosphere. ISME J 6: 756-765.

Whitaker RJ, Grogan DW, Taylor JW. (2003). Geographic barriers isolate endemic populations of hyperthermophilic archaea. Science 301: 976-978.

Yooseph S, Andrews-Pfannkoch C, Tenney A, McQuaid J, Williamson S, Thiagarajan M et al. (2013). A metagenomic framework for the study of airborne microbial communities. PLoS One 8: e81862.

Supplementary Information accompanies this paper on The ISME Journal website (http://www.nature.com/ismej) 